\title{
A CASE OF COELIAC DISEASE SHOWING UNUSUAL FEATURES SUCCESSFULLY TREATED WITH INSULIN AND GLUCOSE
}

\author{
BY \\ BERNARD SCHLESINGER, M.D., F.R.C.P., \\ AND \\ K. D. KEELE, M.D., M.R.C.P. \\ (From the Children's Department, Royal Northern Hospital.)
}

The following case, clinically typical of coeliac disease, is remarkable in that the brunt of the metabolic error falls on carbohydrate rather than on fat metabolism.

History. S. T., male, aged seven years, was first seen in June, 1934, complaining of vomiting. This had begun some months ago and occurred in bouts every two or three weeks, lasting for one day. During this time the abdomen had been noticed to swell. The bowels had always been ' loose.'

Past history. He was a full-time child, never breast fed, and various foods had been tried. He talked and teethed normally, walked at three years and was always stunted.

Family history. Other children healthy; one died 'of 'fits.' The mother had one miscarriage. The home environment was poor.

On examination (June, 1934), the patient was a stunted child with a large abdomen and wasted buttocks (fig. 1). He was mentally listless. His weight was 1 stone $9 \mathrm{lb}$. (Normal for age, 2 st. $12 \mathrm{lb}$.). Signs of active rickets were found clinically and radiologically. Skiagrams also showed multiple, symmetrical fractures of both ulnae and fibulae (fig. 2). An x-ray of skull showed a normal pituitary fossa.

Special inxestigations. The tuberculin (Mantoux test) was negative. A blood count showed:-

R.B.C., 5,200,000 per c.mm.; Hb., 72 per cent.; C.I., 0.65; W.B.C., 14,000 per c.mm.

Differential count: Polys., 6,160 (44 per cent.); lymphos., 7,140 (51 per cent.); monos., 280 ( 2 per cent.); eosins., 420 (3 per cent.). Nucleated reds 280 per c.mm. Anisocytosis and polychromasia were present. The blood urea was $34 \mathrm{mgm}$. per cent. The van den Bergh direct test was negative, the indirect test 0.5 unit. The clinical findings were as follows:-

Before insulin treatment:-Blood calcium, $10 \cdot 1 \mathrm{mgm}$. per cent.; blood phosphorus, $1 \cdot 4 \mathrm{mgm}$. per cent.; blood sugar curve (see fig. 4 (a)) max. rise, 5 mgm. per cent. 
Fat analysis of faeces (fat of diet, $13 \mathrm{gm}$. daily): Split fat, 17 per cent.; unsplit fat, 8 per cent.; total fat, 25 per cent. Repeated fat analysis, total fat, 14 per cent.

After insulin:-Blood calcium, 10 mgm. per cent.; blood phosphorus, 6.4 mgm. per cent.; blood sugar curve max. rise, 30 mgm. per cent. (fig. 4 (b)). Fat analysis of faeces (fat of diet 78 gm.): Split fat, 14 per cent.; unsplit fat, 6 per cent.; total fat, 20 per cent.

Ossification. The outstanding defect in mineral metabolism lay in the poor ossification. Active rickets was present and osteoporosis had reached such a degree that both ulnae and fibulae-the more

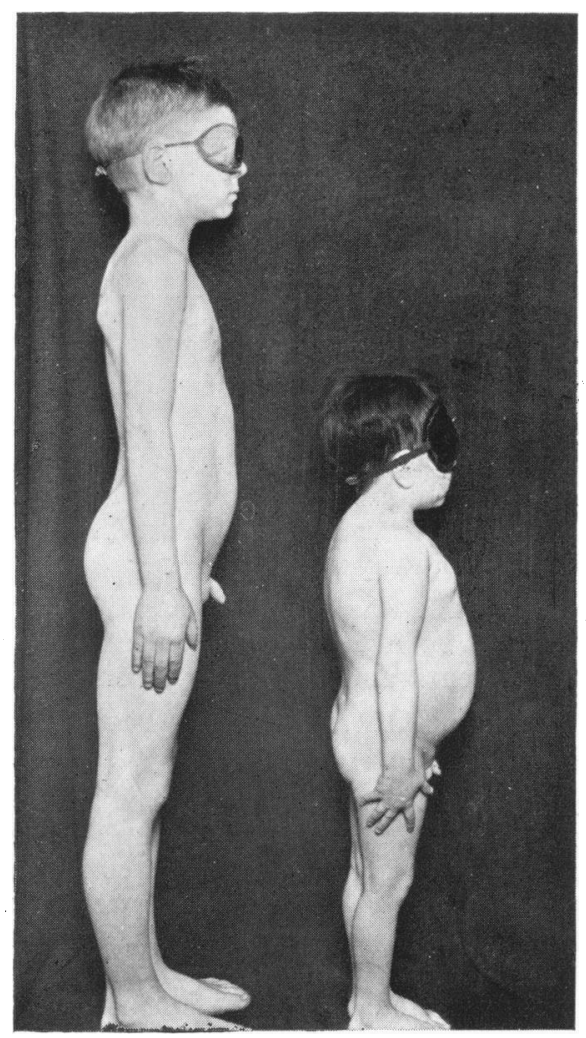

FIG. 1.-Photograph of patient with normal boy of same age (8 yr.). Note the protuberant abdomen and wasted buttocks.

slender long bones-showed symmetrical fractures. It was noteworthy that even when first seen callus had begun to form. The blood calcium, also, was normal (10.1 $\mathrm{mgm}$. per cent.), no doubt in response to the vitamin therapy which had already been in progress for a week or more prior to the chemical investigations. Blood phosphorus, on the other hand, was still markedly deficient, and the picture presented was strikingly that of low phosphorus rickets (Gestenberger). 


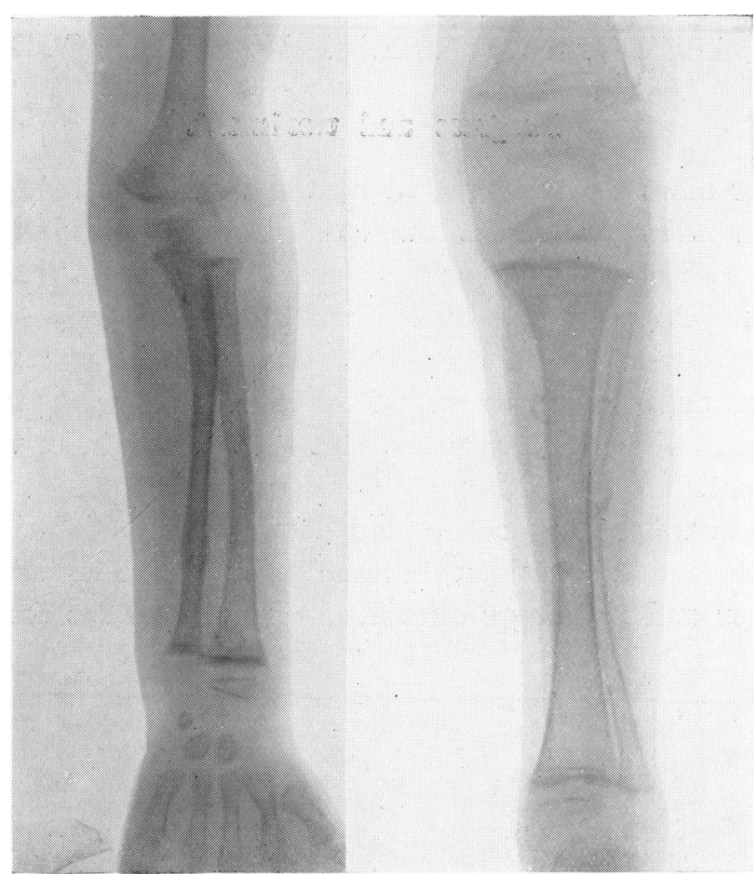

FIG. 2A.-Skiagrams of bones in leg and arm on admission, showing active rickets and multiple symmetrical fractures.

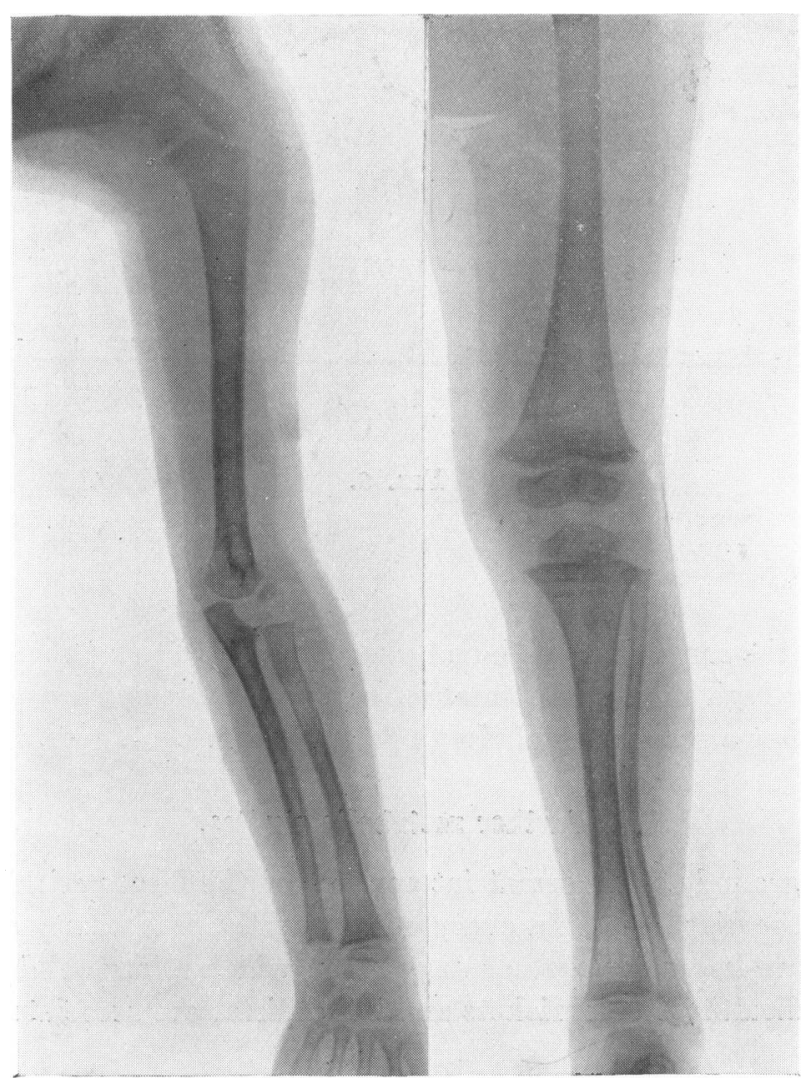

FIG. 2B.-Skiagrams of bones 6 months later. The fractures are united. The rickets is healed. 


\section{Progress and treatment.}

Progress is most clearly depicted by the weight chart (fig. 3). Here it is evident that at first, despite a low fat diet, ultra-violet light, calcium and radiostoleum, loss of weight continued steadily for eight weeks, amounting to $3 \mathrm{lb} .12 \mathrm{oz}$. On beginning insulin and glucose therapy (insulin 3 units, glucose $1.5 \mathrm{gm}$. twice daily), immediate improvement was noticed, with a gain of $4 \mathrm{lb}, 12 \mathrm{oz}$. in seven weeks. Two control periods (' $\mathrm{a}$ ' and ' $\mathrm{b}$ ' on weight chart) are consistent with the fact that this gain in weight was due to the treatment.

The gain in weight was accompanied by general clinical improvement, and the whole mental outlook became brighter. The stools were less frequent, firmer and no longer offensive. Their total fat content remained

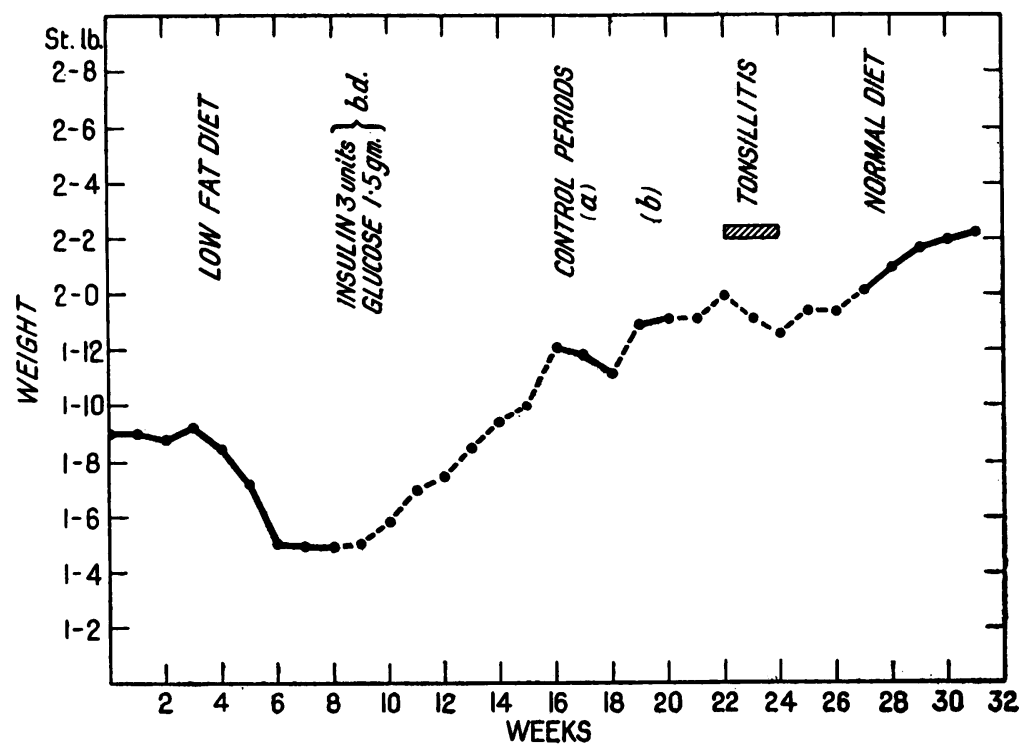

Fig. 3.

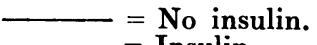

normal. At the same time the blood phosphorus rose to $6.4 \mathrm{mgm}$. per cent.an unusually high figure. Estimation of the blood sugar no longer showed a flat curve but a more normal rise of $30 \mathrm{mgm}$. per cent. (see fig. 4 (b)).

\section{Further metabolic studies.}

On the grounds of a normal fat content of the faeces criticism might be raised as to the diagnosis. In every other way the case was typical of coeliac disease and we know of no other disorder in which a large abdomen, wasted buttocks, unhealthy stools, rickets and infantilism, are associated. 
Carbohydrate metabolism.-The most striking feature of the case was the disordered carbohydrate metabolism. As already stated, a blood sugar curve, with the patient on an ordinary diet and receiving no treatment, was almost flat. On repeating the investigation after a few days' regular administration of glucose and insulin, there was a definite change in the shape of the curve approaching the normal. Finally, after an interrupted treatment of seven weeks, during which the child's general condition showed a dramatic improvement, the insulin and glucose were stopped and an ordinary diet resumed. This did not in any way interfere with his progress.

It was noticed that in spite of the definite clinical improvement, the blood sugar curve reverted to the flat type, not only following the administra-

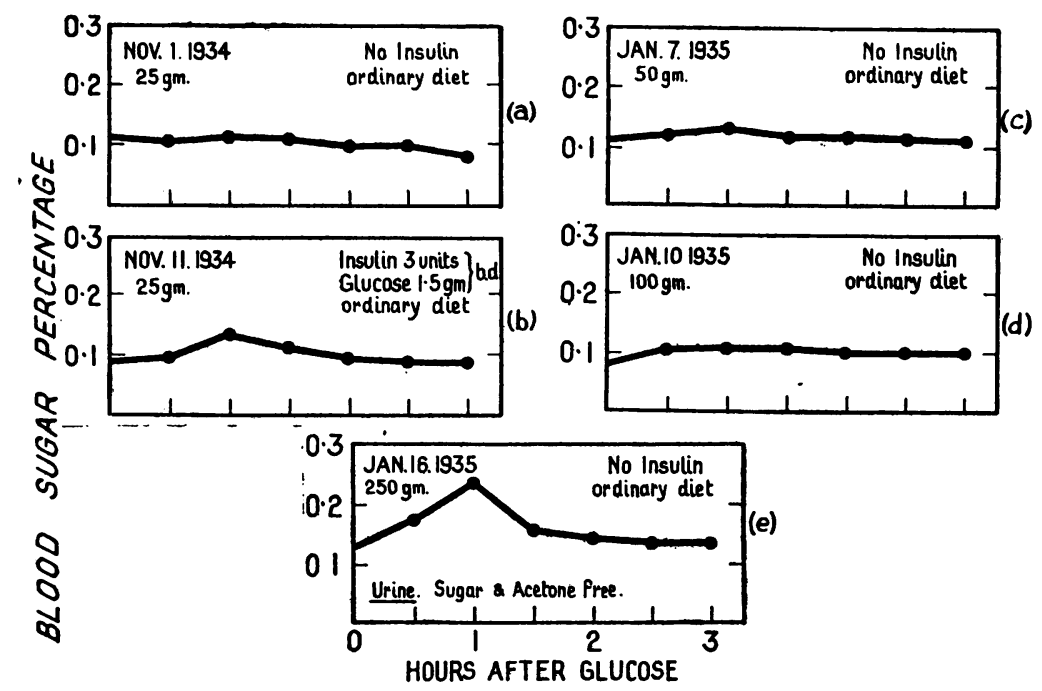

Fig. 4.

tion of $25 \mathrm{gm}$. of glucose by the mouth, the usual standard employed in the test at that age, but even after doses as high as 50 and $100 \mathrm{gm}$. It was only when $250 \mathrm{gm}$. was administered - an extraordinary dose-that a reasonable rise in the blood sugar was observed (to $225 \mathrm{mgm}$. per cent.) (fig. 4 (e)). There was no glycosuria.

Experiments were undertaken to ascertain whether the flat blood sugar curves were due to faulty carbohydrate assimilation. An ordinary diet was given to which was added $100 \mathrm{gm}$. of glucose daily for three days. After a suitable period the experiment was repeated using $250 \mathrm{gm}$. of glucose. The passage through the intestines was followed in each case by a marker (charcoal) and the faeces collected and analysed for soluble carbohydrate. At the same time the blood sugar 
estimations were carried out to which we have already referred. Urine tests throughout the experiment showed the absence of glycosuria. Had there been any faulty carbohydrate assimilation from the alimentary tract present, we would have expected to find a greater quantity of unabsorbed carbohydrate in the faeces following the larger amount of glucose ingested in the second experiment. This did not take place and in both instances the faecal carbohydrate was negligible-over 97 per cent. being absorbed. Lack of absorption from the digestive tract cannot therefore account for the flat blood sugar curves.

\section{Discussion.}

In discussing the aetiology of coeliac disease, emphasis in the past has been laid on errors of fat metabolism, the essential fault lying in a defect in fat absorption. According to Morris and Macrae ${ }^{1}$ there is in health an unlimited absorptive power for fat. In patients with coeliac disease, on the other hand, though there is a rise in absorptive power with a rise in fat intake, this is limited, so that on a high fat diet excess appears in the stools. In the present case the fat content of the faeces did not increase, though the fat in the diet was raised from $13 \mathrm{gm}$. to $78 \mathrm{gm}$. So for this rise, absorptive power increased normally.

It has been suggested by Moncrieff and Payne ${ }^{2}$ that the blood fat is abnormally high in coeliac disease and that the excess in the stools represents an overflow, much in the same way as glycosuria is an overflow of the blood sugar. This attractive theory has not met with general acceptance. Up to the present, no one has paid great attention to abnormalities in carbohydrate metabolism in regard to the aetiology of the disease. Nevertheless, flat blood sugar curves are well recognized ${ }^{3,4,5}$. So constant is this phenomenon that Morris and Macrae state that 'the low blood sugar curve seems to be pathognomonic of the active stage of coeliac disease.'

There are two obvious ways of interpreting this flat blood sugar curve. It may either be due to an increased glycogenic function of the liver, or to a defective absorption from the intestine. Hepatic function as far as carbohydrate is concerned has been found normal ${ }^{1}$ and there are objections to the theory of a defective intestinal absorption. These have been raised by Thaysen and Norgaard" on the grounds that (1) the blood sugar curve remains low after intravenous injections of glucose, (2) the respiratory quotient rises to unity after dextrose injection, and (3) the R.Q. is higher on a carbohydrate diet than on a mixed one. They conclude that the error must be one of metabolism of glucose, not assimilation, and endeavour to explain this on the basis of an endocrine dysfunction.

We realize that the absorption theory has many supporters, in particular Macrae and Morris, but our experience with the present case does not bear this out. The power of alimentary assimilation appeared to be unimpaired; yet the blood sugar curve did not show the normal rise and remained flat 
even after the injection and satisfactory absorption of quite large quantities of glucose. The beneficial influence of insulin both on the blood-sugar curve and the patient's general condition seem to lend strong support to an endocrine disorder in coeliac disease.

There is as yet insufficient evidence to implicate any particular endocrine gland, although the pancreas has always been under suspicion. Poynton and $\mathrm{Cole}^{6}$ have described an isolated instance of coeliac disease with glycosuria. There, however, the pancreatic dysfunction led to an upset of carbohydrate metabolism quite opposite to that observed in our case. Experimentally ligature of the main pancreatic duct in dogs has produced a flat sugar curve ${ }^{5}$. In man it is the faulty action of the pituitary body rather than of the pancreas that is associated with the type of sugar curve under consideration.

Insulin therapy has been used successfully by others in the treatment of coeliac disease (Bellingham-Smith ${ }^{7}$ Budde ${ }^{8}$ ). Both observers were impressed by the dramatic response particularly as regards the weight and the character of the stools.

Coeliac disease is a vague term inasmuch as it indicates nothing further than a disease of the bowel. It is generally held to be primarily a disorder of fat metabolism. Carbohydrate metabolism in our opinion has always been allowed to remain too much in the background of the many researches into the aetiology. On the clinical side, the sudden losses of weight and the equally surprising gains, without any apparent alteration in the stools, could best be explained by an inconstant tissue sugar content and a corresponding irregular storage of water. Finally, we have been impressed by the benefit obtained in desperate cases by the subcutaneous injection of glucose-saline.

\section{Summary.}

1. A patient with clinically typical severe coeliac disease is described, with rickets and symmetrical fractures.

2. Fat analysis of the stools was normal.

3. The brunt of the disorder appeared to be bound up with a faulty carbohydrate metabolism. therapy.

4. Marked clinical improvement was obtained with insulin and glucose

5. The bearing of this and other similar cases in the literature on the aetiology of the disease is discussed. A tentative suggestion is made that a significant part is played by a disordered endocrine system.

Our thanks are due to Dr. Ellison and Dr. Mackenzie of the pathological department for their invaluable co-operation in the investigations of this case. 


\section{REFERENCES}

1. Macrae, O., \& Morris, N., Arch. Dis. Childh., Lond., 1931, VI, 75.

2. Moncrieff, A., \& Payne, W. W., ibid., 1928, III, 257.

3. Fanconi, G., Beiheft. z. Jahrb. f. Kinderheilk., Berlin, 1928, XXI,

4. Maclean, A. B., \& Sullivan, R. C., Am. J. Dis. Child., Chicago, 1929, XXXVIII, 16.

5. Thaysen, T. E. H., \& Norgaard, A., Arch. Int. Med., Chicago, 1929, XLIV, 17, 477.

6. Poynton, F. J., \& Cole, L. B., Brit. Jour. Child. Dis., Lond., 1925, XXII, 30.

7. Bellingham-Smith, G., Arch. Dis. Childh., Lond., 1928, III, 177.

8. Budde, O., Klin. Wchnschr., Berlin, 1927, VI, 973. 